\title{
Transcriptomics of Haemophilus (Glässerella) parasuis serovar 5 subjected to culture conditions partially mimetic to natural infection for the search of new vaccine antigens
}

\author{
Álvaro Álvarez-Estrada, César B. Gutiérrez-Martín *iD, Elías F. Rodríguez-Ferri and Sonia Martínez-Martínez
}

\begin{abstract}
Background: Haemophilus (Glässerella) parasuis is the etiological agent of Glässer's disease in pigs. Control of this disorder has been traditionally based on bacterins. The search for alternative vaccines has focused mainly on the study of outer membrane proteins. This study investigates the transcriptome of $H$. (G.) parasuis serovar 5 subjected to in vitro conditions mimicking to those existing during an infection (high temperature and iron-restriction), with the aim of detecting the overexpression of genes coding proteins exposed on bacterial surface, which could represent good targets as vaccine candidates.

Results: The transcriptomic approach identified 13 upregulated genes coding surface proteins: TbpA, TbpB, HxuA, HxuB, HxuC, FhuA, FimD, TolC, an autotransporter, a protein with immunoglobulin folding domains, another large protein with a tetratricopeptide repeat and two small proteins that did not contain any known domains. Of these, the first six genes coded proteins being related to iron extraction.

Conclusion: Six of the proteins have already been tested as vaccine antigens in murine and/or porcine infection models and showed protection against $H$. (G.) parasuis. However, the remaining seven have not yet been tested and, consequently, they could become useful as putative antigens in the prevention of Glässer's disease. Anyway, the expression of this seven novel vaccine candidates should be shown in other serovars different from serovar 5.
\end{abstract}

Keywords: Haemophilus (Glässerella) parasuis, Glässer's disease, Vaccine antigens, RNA-sequencing, Transcriptome, Iron uptake

\section{Background}

Haemophilus (Glässerella) parasuis is a Gram-negative bacterium which forms part of the microbiota in the upper respiratory tract in pigs. Under certain conditions, such as stress or absence of prior contact, virulent strains can cause a systemic infection resulting in polyserositis, meningitis or arthritis (Glasser's disease) [1]. In addition, $H$. (G.) parasuis is involved in pneumonias as secondary agent within the porcine respiratory complex

\footnotetext{
* Correspondence: cbgutm@unileon.es

Microbiology \& Immunology Section, Animal Health Department, Faculty of Veterinary Medicine, University of León, León, Spain
}

disease [2]. Each year $H$. (G.) parasuis causes significant loss to the swine industry worldwide [1].

Most vaccines used to prevent $H$. (G.) parasuis infection are bacterins although a minory of them are based on live vaccines. These traditional vaccines present several disadvantages, with the main one being the lack of cross-protection against different serotypes [3]. The use of these vaccines has been gradually replaced by subunit vaccines, whose study has been focused on outer membrane proteins (Omps) among other molecules. However, a huge variability has been still found among isolates from different countries, with substantial variations in MLST profiles, in such a manner that problems 
with cross-protection remain [4]. Recent advances in genomics, proteomics and transcriptomics have greatly enabled the search for Omps that are more likely to behave as good vaccine antigens [5].

Most bacteria remodel their coating structures inside the host since they need to adapt to new environments that could be potentially harmful to them, such as high temperature, osmolarity, $\mathrm{pH}$ or oxidative stress and these changes often involve the synthesis of surface structures that are important virulence factors [6]. It has been speculated that the change from a physiological temperature to a higher one (similar to that hyperthermia measured during Glässer's disease) in the host could also be used by some pathogens as a signal to enter into a persistence state in animals that leads to expression of mechanisms triggered during hyperthermia, used to avoid the host immune response. Some of them may correspond to changes in bacterial surface proteins [7].

Although iron is an essential element for organisms, being required for energy processes and DNA, protein or sugar metabolism; however, the concentration of free iron in the host is not enough to support the growth of bacteria [8]. For this reason, pathogenic bacteria have developed different mechanisms to scanvenge iron from host (siderophores, hemophores or host-molecule-binding proteins), which involve the expression of surface-exposed proteins [9]. In this respect, some reports have already concerned the expression of genes of $H$. (G.) parasuis to iron-restriction stress [10-12].

The aim of this work was to study the modifications which occur in the transcriptome of $H$. (G.) parasuis by RNA sequencing, when it is grown in vitro under culture conditions of iron-restriction and temperature stresses. These conditions were selected in order to partially mimic the host environment during natural infection. The transcriptome of bacteria grown under these conditions was compared with that of bacteria grown under optimal in vitro conditions $\left(37^{\circ} \mathrm{C}\right.$ and non-iron-restriction stress) for detecting the overexpression of genes coding proteins exposed on the bacterial surface.

\section{Results}

\section{Quality control of RNA samples}

The RNA integrity from each sample was tested by automated electrophoresis in a Bioanalyzer Agilent 2100. The RNA integrity number (RIN) was not calculated because of the peculiar arrangement of the rRNA peaks from bacteria belonging to genus Haemophilus [22], in which the $23 \mathrm{~S}$ subunit of the rRNA is fragmented in 1.2 and $1.7 \mathrm{~kb}$ portions. However, the graphs showed that the RNA present in each sample had A correct integrity (data not shown).

\section{Upregulation under mimetic conditions (iron-restriction and $41{ }^{\circ} \mathrm{C}$ )}

The number of genes upregulated under these conditions was 433 , of which 154 had a $\log _{2}>10$. Among these 154, there were eight pseudogenes, two genes encoding tRNA and 144 genes encoding proteins (Fig. 1). The amino acid sequence of the proteins encoded by the upregulated genes was obtained, and the cellular location of the proteins and their relation to pathogenesis was investigated. Four extracellular proteins (Eps), 17 Omps, 10 periplasmic proteins (Pps), 13 inner membrane proteins (Imps) and 100 cytoplasmic proteins (Cps) were found using CELLO v.2.5. As the main aim of this study was to search the proteins exposed to the cell surface, we verified individually the location of those proteins that CELLO assigned as belonging to the extracellular and Omp fractions and they were found different. Thus, two of the proteins firstly assigned to Omps were found to be Imps, while three others were Pps and two more were Cps. One of the Eps and another protein initially assigned to Omps appeared to be really the same extracellular protein but they were noted as two different proteins in the reference genome because of a point mutation involving the emergence of a stop codon. Therefore, after this correction, four proteins remained assigned to an extracellular localization (Eps), nine as Omps, 15 as Imps, 13 as Pps and 102 as Cps (Fig. 1).

A total of 31 proteins were recognized as being related to pathogenesis and therefore possibly involved in the pathogenesis of Glässer's disease (Fig. 1), and of them, four were Eps, nine were Omps, six were Imps, five were Pps and seven were Cps. All proteins predicted to be located on the bacterial surface were also predicted as being related to pathogenesis.

Table 1 shows the upregulated proteins that were predicted to be located on the bacterial surface (Omps or Eps) and/or related to pathogenesis. The proteins predicted to be located on the bacterial surface or related to pathogenes is that were not identified in GenBank and Uniprot databases were subjected to further studies of sequence homology and searched for the presence of domains of a known function. The findings are shown in Table 2. Additional file 1 summarizes the findings for genes that were upregulated under mimetic conditions with a $\log _{2}$ (fold change) $>10$.

\section{Downregulation under mimetic conditions (without iron- restriction and $37^{\circ} \mathrm{C}$ )}

The number of genes underexpressed under control conditions was 460 , of which 187 were selected for having a $\log _{2}>10$. They included four pseudogenes, seven genes encoding tRNA, another gene encoding rRNA and 175 genes encoding proteins (Fig. 2). The CELLO v.2.5 program predicted six Eps, five Omps, 34 Imps, 30 Pps 

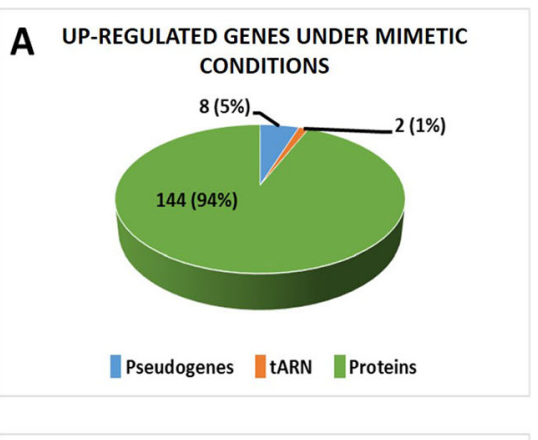

C RELATIONSHIP WITH PATHOGENESIS OF UP-REGULATED PROTEINS

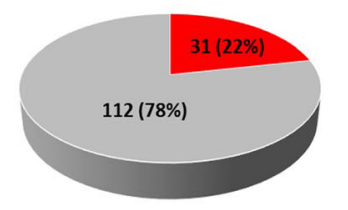

IPathogeny || No pathogeny

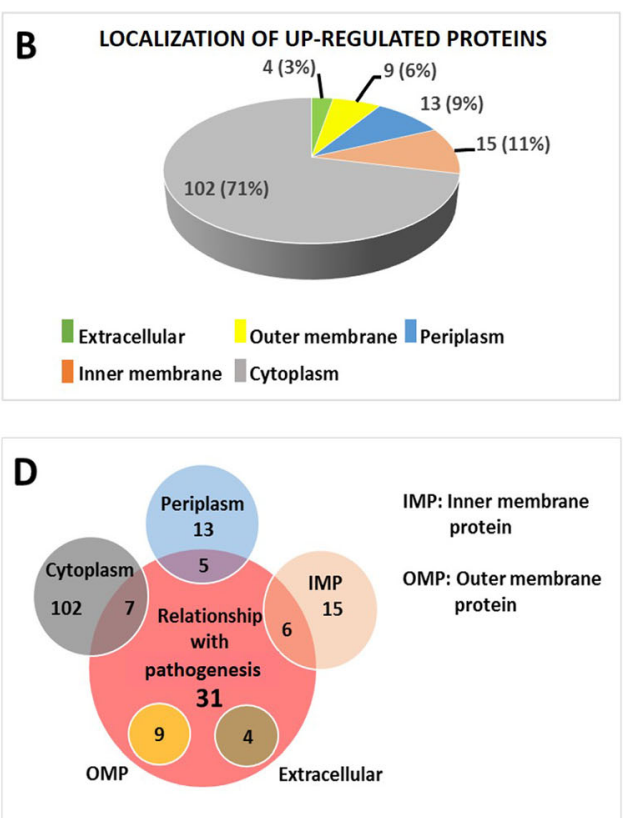

Fig. 1 Genes and proteins upregulated under mimetic conditions. (a): Number of pseudogenes, tRNA and protein-coding genes indicating the percentage of the total number of upregulated genes with $\log _{2}$ (fold change) $>10$ under mimetic conditions. (b): Number of different locations of proteins upregulated under mimetic conditions and percentage of total proteins. Further corrections were taken into account. (c): Number and percentage of proteins related to pathogenesis upregulated under mimetic conditions. Further corrections were considered. (d): Venn diagram representing the relationship between cell localization and the pathogenesis of upregulated proteins. Further corrections were taken into account

and 100 Cps. Those assigned as Omps or Eps were individually rechecked and, after correction, four proteins remained assigned as Omps wihle the number of Cps rose to 101 (Fig. 2). The MP3 server found 34 proteins that were recognized as being related to pathogenesis (Fig. 2), of which five were Eps, three were Omps, 13 were Imps, eight were Pps and five were Cps. Additional file 2 summarizes findings for genes that were downregulated under mimetic conditions with a $\log 2>10$.

\section{Gene ontology (GO) term enrichment analysis}

Among the genes upregulated under mimetic conditions, only the GO term GO:0003676 (nucleic acid binding) was found to be enriched and associated with the presence in 37 upregulated genes (Table 3). With regard to genes downregulated under mimetic conditions, 31 GO terms were classified as being enriched (Table 4).

\section{Discussion}

Most bacteria reshape their coating structures inside the host since they need to adapt to a new potentially harmful environment [6]. Although the environment that a microorganism endures inside the host is much more complex than that replicated in the laboratory, the two selected conditions in this study (iron-restriction and temperature higher than $37^{\circ} \mathrm{C}$ ) attempted to partially simulate the infection in natural conditions. Some reports have been carried out on the changes occurring in the $H$. (G.) parasuis transcriptome when this bacterium was subjected to these two mimetic conditions of high temperature and iron scarcity [10, 12, 23]. However, the two circumstances in those studies were not tested together because these studies were focused in the understanding of both metabolism and virulence factors but not to search putative candidates that could be used as vaccine antigens.

The bacterial mechanisms used to remove iron from the host need surface-exposed proteins [9], and their expression is induced by a low iron concentration [24]. Among the genes upregulated under mimetic conditions, we detected six genes coding for Eps or Omps related to the obtaining of iron from the host (TbpA, TbpB, HxuA, HxuB, HxuC and FhuA). In a previous study of the transcriptome of $H$. (G.) parasuis exposed to the intraalveolar environment for two hours, upregulation of genes encoding membrane proteins involved in iron uptake were detected [25]. This finding reinforces our results concerning the high probability that the six above mentioned genes will be overexpressed during infection with $H$. (G.) parasuis.

TbpA and TbpB are porcine transferrin binding proteins that show different protection degrees against Glässer's disease [26, 27]. HxuA, HxuB and HxuC correspond to hemophore, transporter and receptor of the heme/ hemopexin-binding protein (hxu) operon, respectively 
Table 1 Upregulated proteins under mimetic conditions related to pathogenesis and located on the bacterial surface

\begin{tabular}{|c|c|c|c|c|c|}
\hline Locus $^{a}$ & GenBank product & $\begin{array}{l}\text { Access number } \\
\text { Uniprot }\end{array}$ & Name Uniprot & Pathogenesis & Location \\
\hline HAPS_RS00370 & protein TolA & B8F375 & $\begin{array}{l}\text { |tolA|Cell envelope integrity inner } \\
\text { membrane protein TolA }\end{array}$ & $P$ & $\mathrm{IM}$ \\
\hline HAPS_RS00485 & TonB-dependent receptor & - & - & $P$ & $\mathrm{OM}$ \\
\hline HAPS_RS00735 & hypothetical protein & - & - & $P$ & $\mathrm{OM}$ \\
\hline HAPS_RSO0740 & $\begin{array}{l}\text { autotransporter domain-containing } \\
\text { protein }\end{array}$ & - & - & $\mathrm{P}$ & $\mathrm{OM}^{\mathrm{a}}$ \\
\hline HAPS_RSO0745 ${ }^{\mathrm{a}}$ & hypothetical protein & - & - & $P$ & EX \\
\hline HAPS_RS01255 & $\mathrm{ABC}$ transporter permease & $\mathrm{B} 8 \mathrm{~F} 3 \mathrm{P} 0$ & $\begin{array}{l}\text { |HAPS_0253|ABC-type nitrate/sulfonate/bicarbonate } \\
\text { transport permease }\end{array}$ & $P$ & $\mathrm{IM}$ \\
\hline HAPS_RS01260 & $\begin{array}{l}\text { ABC transporter substrate-binding } \\
\text { protein }\end{array}$ & B8F3P1 & $\begin{array}{l}\text { |HAPS_0254|ABC-type nitrate/sulfonate/bicarbonate } \\
\text { transport systems periplasmic components protein }\end{array}$ & $P$ & $C P$ \\
\hline HAPS_RS01265 & ABC transporter ATP-binding protein & $\mathrm{B} 8 \mathrm{~F} 3 \mathrm{P} 2$ & $\begin{array}{l}\text { |HAPS_0255|ABC-type nitrate/sulfonate/bicarbonate } \\
\text { transport system, ATPase }\end{array}$ & $P$ & $\mathrm{IM}$ \\
\hline HAPS_RS01400 & sulfurtransferase FdhD & - & - & $P$ & $\mathrm{CP}$ \\
\hline HAPS_RSO1435 & hypothetical protein & $\mathrm{B} 8 \mathrm{~F} 3 \mathrm{~S} 4$ & |HAPS_0289|Uncharacterized protein & $P$ & $\mathrm{CP}$ \\
\hline HAPS_RS01805 & ABC transporter ATPase & $\mathrm{B} 8 \mathrm{~F} 3 \mathrm{Z5}$ & $\begin{array}{l}\text { |HAPS_0364|ATPase components of ABC transporters } \\
\text { with duplicated ATPase domains-containing protein }\end{array}$ & $P$ & PP \\
\hline HAPS_RS01895 & hypothetical protein & $\mathrm{B} 8 \mathrm{~F} 410$ & |HAPS_0382|Uncharacterized protein & $P$ & EX \\
\hline HAPS_RS02610 & hypothetical protein & B8F4D5 & |purL|Phosphoribosylformylglycinamidine synthase & $P$ & $\mathrm{CP}$ \\
\hline HAPS_RS03735 & fimbrial usher protein & - & - & $P$ & $\mathrm{OM}$ \\
\hline HAPS_RS04480 & hypothetical protein & - & - & $\mathrm{P}$ & PP \\
\hline HAPS_RS04485 & hypothetical protein & B8F5E9 & |HAPS_0923|Uncharacterized protein & $P$ & EX \\
\hline HAPS_RS06520 & hypothetical protein & B8F6H3 & |yaaH|Permease, Inner membrane protein yaaH & $P$ & $\mathrm{IM}$ \\
\hline HAPS_RS00370 & protein TolA & $\mathrm{B} 8 \mathrm{~F} 375$ & $\begin{array}{l}\text { |tolA|Cell envelope integrity inner membrane } \\
\text { protein TolA }\end{array}$ & $P$ & IM \\
\hline HAPS_RS00485 & TonB-dependent receptor & - & - & $P$ & $\mathrm{OM}$ \\
\hline HAPS_RS00735 & hypothetical protein & - & - & $P$ & $\mathrm{OM}$ \\
\hline HAPS_RSO0740 & $\begin{array}{l}\text { autotransporter domain-containing } \\
\text { protein }\end{array}$ & - & - & $P$ & $\mathrm{OM}$ \\
\hline HAPS_RS00745 & hypothetical protein & - & - & P & EX \\
\hline HAPS_RS06610 & cell envelope protein TonB & $\mathrm{B} 8 \mathrm{~F} 6 \mathrm{~J} 2$ & |tonB|Protein TonB & $P$ & PP \\
\hline HAPS_RS07630 & iron $\mathrm{ABC}$ transporter permease & $\mathrm{B} 8 \mathrm{~F} 723$ & $\begin{array}{l}\mid \text { hmuU|Hemin transport system permease } \\
\text { protein HmuU }\end{array}$ & $P$ & IM \\
\hline HAPS_RS07950 & hypothetical protein & - & - & $P$ & $\mathrm{CP}$ \\
\hline HAPS_RS09000 & hypothetical protein & B8F7Q0 & |HAPS_1850|Uncharacterized protein & $P$ & $\mathrm{IM}$ \\
\hline HAPS_RS10195 & DUF262 domain-containing protein & B8F899 & |HAPS_2100|Uncharacterized protein & $P$ & $\mathrm{CP}$ \\
\hline HAPS_RS10530 & TolC family protein tolC & $\mathrm{B} 8 \mathrm{~F} 8 \mathrm{~F} 2$ & $\begin{array}{l}\text { |tolC|RND efflux system outer membrane } \\
\text { lipoprotein/RND superfamily resistance- } \\
\text { nodulation-cell division antiporter }\end{array}$ & $P$ & $\mathrm{OM}$ \\
\hline HAPS_RS10585 & ligand-gated channel & B8F8G2 & $\begin{array}{l}\text { |hxuC|Heme/hemopexin utilization protein C/outer } \\
\text { membrane receptor protein, mostly Fe transport }\end{array}$ & $P$ & $\mathrm{OM}$ \\
\hline HAPS_RS10590 & $\begin{array}{l}\text { ShlB/FhaC/HecB family hemolysin } \\
\text { secretion/activation protein }\end{array}$ & B8F8G3 & $\begin{array}{l}\text { hxuB|Heme/hemopexin-binding protein B, } \\
\text { hemolysin activation/secretion protein }\end{array}$ & $P$ & $\mathrm{OM}$ \\
\hline HAPS_RS10595 & hypothetical protein & B8F8G4 & $\begin{array}{l}\mid \text { hxuA|Heme/hemopexin-binding protein A } \\
\text { (Heme:hemopexin utilization protein A) }\end{array}$ & $P$ & EX \\
\hline HAPS_RS10780 & membrane protein & B8F8J9 & $\begin{array}{l}\text { |HAPS_2219|Possible outer membrane protein/FOG: } \\
\text { TPR repeat protein }\end{array}$ & $P$ & $\mathrm{OM}$ \\
\hline HAPS_RS10800 & $\begin{array}{l}\text { transferrin-binding protein-like solute } \\
\text { binding protein }\end{array}$ & - & - & $P$ & $\mathrm{OM}$ \\
\hline
\end{tabular}


Table 1 Upregulated proteins under mimetic conditions related to pathogenesis and located on the bacterial surface (Continued)

\begin{tabular}{|c|c|c|c|c|c|}
\hline Locus $^{a}$ & GenBank product & $\begin{array}{l}\text { Access number } \\
\text { Uniprot }\end{array}$ & Name Uniprot & Pathogenesis & Location \\
\hline HAPS_RS10805 & $\begin{array}{l}\text { lactoferrin/transferrin family } \\
\text { TonB-dependent receptor }\end{array}$ & B8F8K4 & |tbpA|Transferrin-binding protein 1 & $P$ & $\mathrm{OM}$ \\
\hline HAPS_RS11010 & transpeptidase & B8F8P5 & |HAPS_2267|Uncharacterized protein & $\mathrm{P}$ & PP \\
\hline HAPS_RS11030 & transcriptional regulator & B8F8P9 & |impA|SOS-response transcriptional repressor & $P$ & $C P$ \\
\hline
\end{tabular}

$P$ indicates the relationship to pathogenesis; Locations are indicated by: $O M$ outer membrane, $E X$ extracellular, $I M$ inner membrane, $P P$ periplasmic, $C P$ cytoplasmic. The locus in the reference genome (SH0165 strain) is indicated. ${ }^{a}$ indicates that this was a single protein recognized as two different ones.

[28]. A protection of $87.5 \%$ for $\mathrm{HxuC}, 62.5 \%$ for $\mathrm{HxuB}$ and $37.5 \%$ for HxuA has been recently showed in mice against $H$. (G.) parasuis [29]. The upregulated gene HAPS_RS00485, coding for FhuA protein, a receptor for siderophores, has not been tested as vaccine antigen until date [30]. Curiously, Melnikow et al. [10] did not find fhuA among the genes upregulated under iron-restrictive conditions. One possible explanation for the difference between this study and ours could be that the combination of both conditions is required for upregulation of this gene.

Depending on the bacterial species, fever could cause a heat stress [31] that triggered changes involving coating structures [6]. It would be therefore expected that the reprogramming of the transcriptome undergone by the bacterium to resist heat stress could affect some genes encoding for surface-exposed proteins. The upregulated gene tolC found in this study encodes an Omp (TolC) lipoprotein that forms a trimeric channel and acts in the transport of several molecules [32]. Li et al. [33] observed that mice immunized with this protein and then challenged with $H$. (G.) parasuis showed a survival rate of $80 \%$.

In addition to these well-characterized proteins in the databases, another five proteins were predicted to be located on the bacterial surface (Eps or Omps). The largest of them was an autotransporter with a serine protease domain which is annotated as two different genes
(HAPS_RS00740 and HAPS_RS00745) in the reference genome (SH0165 strain) because it presents a punctual mutation that triggers off the appearance of a stop codon. This long protein presents a broad sequence homology with the AasP autotransporter of A. pleuropneumoniae, which it is upregulated when this bacterium is grown under iron restriction stress [34]. On the other hand, a previous study performed with an AasP mutant in A. pleuropneumoniae showed that AasP protein is involved in adhesion under iron-restriction conditions [35].

The upregulated gene HAPS_RS04485 codes a protein that harbors domains with an immunoglobulin-like fold, which are usually present in proteins related to invasion or adhesion in prokaryotes [36]. Among the three remaining surface proteins whose genes were upregulated, two of them (HAPS_RS00735 and HAPS_RS01895) neither presented homology to known proteins nor harbored domains with a known function, while in the remaining one (HAPS_RS10780) only a $\beta$-barrel and a single tetratricopeptide repeat could be detected.

With regard to the functional enrichment analysis under mimetic conditions to natural infection, only one significant enrichment was observed in the GO term 0003676, corresponding to nucleic acid binding, which was found in 37 upregulated genes. This could be consistent with the important reprogramming, at both transcriptional and translational levels, which the bacteria

Table 2 Findings in upregulated proteins under mimetic conditions related to pathogenesis but not characterized in the databases

\begin{tabular}{llll}
\hline LOCUS & Access number Uniprot & Location & Findings \\
\hline HAPS_RS00735 & - & $\mathrm{OM}$ & Nothing was recognized \\
HAPS_RS00740 & - & $\mathrm{OM}^{\mathrm{a}}$ & Half C-terminal Carrier ${ }^{\mathrm{a}}$ \\
HAPS_RS00745 & - & $\mathrm{EX}^{\mathrm{a}}$ & Half -terminal auto transporter ${ }^{\mathrm{a}}$ \\
HAPS_RS01435 & $\mathrm{B} 8 \mathrm{~F} 3 \mathrm{~S} 4$ & $\mathrm{CP}$ & Nothing was recognized \\
HAPS_RS01895 & B8F410 & $\mathrm{EX}$ & Nothing was recognized \\
HAPS_RS04480 & - & $\mathrm{PP}$ & Domain of the superfamily Glycoside-hydrolase \\
HAPS_RS04485 & B8F5E9 & EX & Immunoglobulin-like fold domain \\
HAPS_RS07950 & - & $\mathrm{CP}$ & Domain of the Thioredoxin-like superfamily \\
HAPS_RS09000 & B8F7Q0 & IM & Homology with permease \\
HAPS_RS10195 & B8F899 & $\mathrm{CP}$ & ParB-like and HNH nuclease domains
\end{tabular}

The locus in the reference genome (SH0165 strain) is also indicated. ${ }^{a}$ indicates that this was a single protein recognized as two different ones 


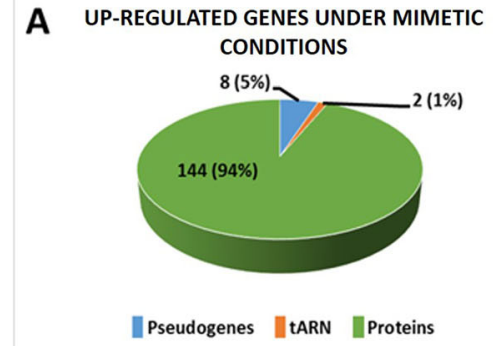

C RELATIONSHip With PATHOGENESIS OF UP-REGULATED PROTEINS

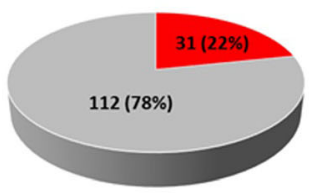

IPathogeny || No pathogeny
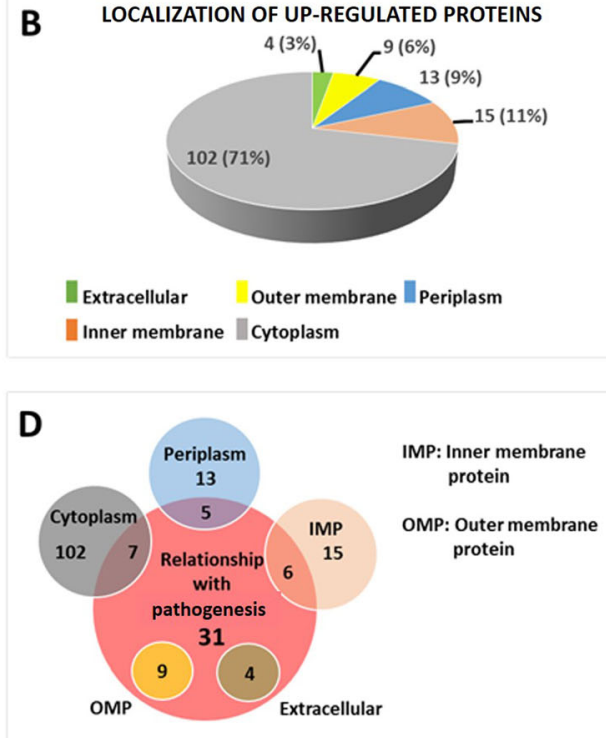

Fig. 2 Genes and proteins downregulated under mimetic conditions. (a): Number of pseudogenes, tRNA and protein-coding genes indicating the percentage of the total number of genes down regulated genes with $\log _{2}$ (fold change) $>10$ under mimetic conditions. (b): Number of different locations of proteins downregulated under mimetic conditions and percentage of total proteins. Further corrections were taken into account. (c): Number and percentage of proteins related to pathogenesis downregulated under mimetic conditions. Further corrections were considered. (d): Venn diagram representing the relationship between cell localization and the pathogenesis of downregulated proteins. Further corrections were taken into account

Table 3 List of upregulated genes where GO term GO:0003676 (nucleic acid binding) was found

\begin{tabular}{|c|c|c|c|}
\hline Locus & GenBank product & Locus & GenBank product \\
\hline HAPS_RS06635 & tRNA-dihydrouridine synthase & HAPS_RS06640 & Fis family transcriptional regulator \\
\hline HAPS_RS07775 & $30 \mathrm{~S}$ ribosomal protein $\mathrm{S} 10$ & HAPS_RS07795 & $50 S$ ribosomal protein L2 \\
\hline HAPS_RS01040 & LysR family transcriptional regulator & HAPS_RS07785 & $50 S$ ribosomal protein $L 4$ \\
\hline HAPS_RS03460 & tRNA pseudouridine (65) synthase TruC & HAPS_RS01015 & translation initiation factor IF-2 \\
\hline HAPS_RS07435 & MurR/RpiR family transcriptional regulator & HAPS_RS07790 & 50 S ribosomal protein L23 \\
\hline HAPS_RS02800 & transcriptional regulator & HAPS_RS10775 & ATPase AAA \\
\hline HAPS_RSO2140 & transcriptional regulator & HAPS_RS06525 & Holliday junction DNA helicase RuvA \\
\hline HAPS_RS09580 & $23 \mathrm{~S}$ rRNA (guanosine-2'-O-)-methyltransferase & HAPS_RS07720 & RNA polymerase, beta subunit \\
\hline HAPS_RS08560 & restriction endonuclease & HAPS_RS01010 & transcription termination factor NusA \\
\hline HAPS_RS09560 & $30 S$ ribosomal protein $\mathrm{S7}$ & HAPS_RS07780 & $50 S$ ribosomal protein $\mathrm{L} 3$ \\
\hline HAPS_RS09565 & elongation factor $G$ & HAPS_RS01395 & elongation factor Ts \\
\hline HAPS_RS08275 & endonuclease & HAPS_RS02855 & single-stranded DNA-binding protein \\
\hline HAPS_RS10985 & Fur family transcriptional regulator & HAPS_RS00670 & transposase \\
\hline HAPS_RS02340 & RNA helicase & HAPS_RS10560 & transcriptional regulator \\
\hline HAPS_RS04055 & DNA polymerase III subunit epsilon & HAPS_RS03180 & 50 S ribosomal protein L25 \\
\hline HAPS_RS01380 & lysine tRNA synthetase & HAPS_RS04045 & heat-shock protein \\
\hline HAPS_RS08565 & restriction endonuclease & HAPS_RS01070 & tRNA s (4) U8 sulfurtransferase \\
\hline HAPS_RS08440 & transcriptional regulator & HAPS_RS04180 & formamidopyrimidine-DNA glycosylase \\
\hline HAPS_RS05455 & DNA-binding protein & & \\
\hline
\end{tabular}


Table 4 GO terms found to be enriched among downregulated genes under mimetic conditions

\begin{tabular}{|c|c|c|}
\hline GO term & GO domain & Number of genes \\
\hline GO:0008643 carbohydrate transport & $\mathrm{BP}$ & 16 \\
\hline GO:0015980 energy derivation by oxidation of organic compounds & $\mathrm{BP}$ & 17 \\
\hline GO:0055114 oxidation-reduction process & $\mathrm{BP}$ & 21 \\
\hline GO:0009401 phosphoenolpyruvate-dependent sugar phosphotransferase system & $\mathrm{BP}$ & 13 \\
\hline GO:0009401 phosphoenolpyruvate-dependent sugar phosphotransferase system & $\mathrm{BP}$ & 13 \\
\hline GO:0006091 generation of precursor metabolites and energy & $\mathrm{BP}$ & 19 \\
\hline GO:0045333 cellular respiration & $\mathrm{BP}$ & 14 \\
\hline GO:0006099 tricarboxylic acid cycle & $\mathrm{BP}$ & 10 \\
\hline GO:0006099 tricarboxylic acid cycle & $\mathrm{BP}$ & 10 \\
\hline GO:0009060 aerobic respiration & $\mathrm{BP}$ & 10 \\
\hline GO:0044712 single-organism catabolic process & $\mathrm{BP}$ & 17 \\
\hline GO:0044699 single-organism process & $\mathrm{BP}$ & 73 \\
\hline GO:0005975 carbohydrate metabolic process & $\mathrm{BP}$ & 25 \\
\hline GO:0044724 single-organism carbohydrate catabolic process & $\mathrm{BP}$ & 11 \\
\hline GO:0044282 small molecule catabolic process & $\mathrm{BP}$ & 12 \\
\hline GO:0016052 carbohydrate catabolic process & $\mathrm{BP}$ & 11 \\
\hline GO:1901575 organic substance catabolic process & $\mathrm{BP}$ & 18 \\
\hline GO:1901476 carbohydrate transporter activity & MF & 8 \\
\hline GO:0015144 carbohydrate transmembrane transporter activity & MF & 8 \\
\hline GO:0044765 single-organism transport & $\mathrm{BP}$ & 23 \\
\hline GO:0009056 catabolic process & $\mathrm{BP}$ & 18 \\
\hline GO:0005996 monosaccharide metabolic process & $\mathrm{BP}$ & 10 \\
\hline GO:1902578 single-organism localization & $\mathrm{BP}$ & 23 \\
\hline GO:0071702 organic substance transport & $\mathrm{BP}$ & 17 \\
\hline GO:0044723 single-organism carbohydrate metabolic process & $\mathrm{BP}$ & 17 \\
\hline GO:0006810 transport & $\mathrm{BP}$ & 26 \\
\hline GO:0019318 hexose metabolic process & $\mathrm{BP}$ & 8 \\
\hline GO:0051179 localization & $\mathrm{BP}$ & 26 \\
\hline GO:0051234 establishment of localization & $\mathrm{BP}$ & 26 \\
\hline GO:0044710 single-organism metabolic process & $\mathrm{BP}$ & 49 \\
\hline GO:0046365 monosaccharide catabolic process & $\mathrm{BP}$ & 5 \\
\hline
\end{tabular}

The number of genes where each GO term was found is indicated. The gene ontology domain (GO domain) to which each GO term belongs is also indicated, $B P$ biological process, MF molecular function

undergo when exposed to environmental stress [37]. Among these genes, six coded ribosomal subunit binding proteins, four coded rRNA-related enzymes (translational level) and eight coded transcriptional regulators (transcriptional level). Within the upregulated transcriptional regulators, the iron uptake regulatory protein (Fur) must be highlighted. This protein forms a dimer in the presence of $\mathrm{Fe}^{2+}$ that represses the expression of genes related to iron uptake. However, when available iron is scarce, this dimer breaks down and transcription of genes related to iron uptake is allowed [38]. The upregulation of a negative regulator of iron acquisition under iron-restricted conditions may be paradoxical effect; however, different findings have been shown over the last years that the role of Fur is not as simple as it had been previously stated although it remains fully valid. There are positively regulated genes for Fe-induced Fur dimers and other positively or negatively regulated genes for Fur when this protein does not form a complex with $\mathrm{Fe}^{2+}$. Some of the genes that are regulated in these ways are related to the response to stressful conditions or to virulence [38]. Therefore, it was not unusual to find Fur gene among those upregulated under our stress conditions.

Concerning functional enrichment analysis of downregulated genes under mimetic conditions, the most 
enriched terms were related to energy metabolism, redox reactions, or to both of them. Relative to energy metabolism, this finding would make sense with slowing of growth braking expected in a stressful environment, which should result in a general decrease in the metabolism. In the case of redox processes, it might simply be a reflection of the decrease in bacterial growth and/or it could be that the microorganism, when detecting iron deficiency, prefers not to waste energy in the production of compounds that cannot perform their function since the iron is the main limiting factor [9].

As previously mentioned, microorganisms have to face a number of stressors during infection, such as unfavorable temperatures, $\mathrm{pH}$ changes or free radicals, which trigger the expression of several proteins known as cellular stress proteins [39]. These proteins behave as chaperones promoting the assembly of other macromolecules and are often called heat shock proteins (Hsp) since it was previously believed that they acted alone against heat stress [40]. Several genes encoding different Hsp were upregulated in our study, such as DnaJ, DnaK, HslO and HslR. Several Hsp behaving as surface antigens were observed, which might seem a contradiction considering that the role played as chaperones should imply an intracellular location. However, many of these proteins, in addition to act as chaperones, also present functions related to pathogenesis that may imply a superficial location [40]. Accordingly, it would be reasonable to study these proteins as vaccine antigens; however, it would not be appropriate to do because Hsp have been highly conserved throughout evolution and there is a high homology between the Hsp from bacterial and those from mammalian origin. For this reason, the use of Hsp as vaccine antigens could trigger autoimmune diseases [39].

\section{Conclusion}

Slowing of growth expected in stressful conditions have given rise to the upregulation of $13 \mathrm{H}$. (G.) parasuis genes coding for proteins located on the bacterial surface. Among them, seven proteins untested to date were detected as vaccine antigens: FhuA (encoded by HAPS_RS00485), a fimbrial usher protein (encoded by HAPS_RSO3735), a long autotransporter (encoded by HAPS_RSO0740 and HAPS_RS00745), a protein containing domains with an Ig-like fold (encoded by HAPS_RS04485) and other three surface proteins without known function (encoded by HAPS_RS10780, HAPS_RS00735 and HAPS_RS01895). These seven novel vaccine candidates could provide protection against Glässer disease, but their effectiveness have to be tried in future studies. Anyway, their expression must be sustained in other serovars different from serovar 5 .

\section{Methods}

\section{Bacterial strain and growth conditions}

$H$. (G.) parasuis was grown under (i) in vitro optimal culture conditions (control conditions) and (ii) under in vitro growth conditions partially mimicking the host environment encountered during infection (iron-restriction and temperature stress by raising incubation temperature above $37^{\circ} \mathrm{C}$ ). The transcriptomes from both growths were compared by RNA sequencing to detect overexpressed genes coding proteins exposed on the bacterial surface.

For control culture conditions (without iron-restriction and $37{ }^{\circ} \mathrm{C}$ ), $H$. (G.) parasuis Nagasaki strain (reference strain of serovar 5 kindly supplied by Kielstein P., Federal Institute for Health Protection of Consumers and Veterinary Medicine, Jena, Germany) was inoculated into $30 \mathrm{ml}$ of PPLO broth (Conda Laboratories, Spain) with $150 \mu \mathrm{M}$ nicotinamide adenine dinucleotide (NAD, Sigma-Aldrich, Spain) and $0.075 \%$ glucose (Sigma-Aldrich), and it was cultured at $37^{\circ} \mathrm{C}$ until reaching an optical density of 0.5 at $600 \mathrm{~nm}\left(\mathrm{OD}_{600}\right)$. Three replicates were made under these conditions. For mimetic conditions (iron-restriction and $\left.41{ }^{\circ} \mathrm{C}\right), H$. (G.) parasuis Nagasaki strain was inoculated into $30 \mathrm{ml}$ of the same broth and was cultured at $41{ }^{\circ} \mathrm{C}$ until reaching an $\mathrm{OD}_{600}$ of 0.3 . Then, iron was restricted by adding $200 \mu \mathrm{M} 22^{\prime}$-dipyridyl, and the culture was grown again at $41{ }^{\circ} \mathrm{C}$ to an $\mathrm{OD}_{600}$ of 0.5 . Three replicates were also made.

\section{RNA extraction and sample preparation}

When the appropriate $\mathrm{OD}_{600}$ was reached for each replicate, the culture was centrifuged at $7000 \times g$ and $4{ }^{\circ} \mathrm{C}$ for $7 \mathrm{~min}$. The supernatants were removed and the pellets were preserved on ice. RNA extraction was performed using the High Pure RNA Isolation kit (Sigma-Aldrich) following the manufacturer's specifications. The DNA-free kit (Thermo-Fisher) was used to remove the contaminating DNA, which was verified by species-specific PCR [13], testing the absence of amplification in samples treated with DNAse. Finally, RNA concentrations were measured in a NanoDrop 1000 (Thermo-Fisher), and samples were stored at $-80{ }^{\circ} \mathrm{C}$. The RNA integrity checking was tested using a Bioanalyzer Agilent 2100 (Agilent Technologies, Spain) from the Laboratory of Instrumental Techniques (University of León, Spain).

\section{Library preparation and Illumina sequencing}

Ribosomal RNA (rRNA) was removed from the samples using a Ribo-Zero Magnetic Kit Bacteria (Illuminia, Portugal). Libraries were then prepared following the instructions of the NEBNext Ultra Directional RNA Library Prep kit for Illumina (New England Biolabs, USA). The input of ribosome-depleted RNA to start the protocol was $10 \mathrm{ng}$ quantified by an Agilent 2100 Bioanalyzer 
using a RNA 6000 nano LabChip kit (Agilent Technologies, Germany). The fragmentation time used was 15 min. The cDNA libraries obtained were validated and quantified by an Agilent 2100 Bioanalyzer using a DNA7500 LabChip kit (Agilent Technologies). An equimolecular pool of libraries were titrated by quantitative PCR using the Kapa-SYBR FAST qPCR kit for LightCycler480 (Kapa BioSystems, USA), and a reference standard for quantification. The pool of libraries was denatured prior to be seeded on a flowcell at a density of 2 $2 \mathrm{pM}$, where clusters were formed and sequenced with a depth of $10 \mathrm{M}$ using a NextSeq 500 High Output Kit (Illumin) in a $1 \times 75$ single-read sequencing run on a NextSeq 500 sequencer (Illumin).

\section{Bioinformatic analysis of differential gene expression}

Bioinformatic analysis for the RNAseq data was performed by Era7 bioinformatics (Spain) following the protocol described by Trapnell et al. [14]. Quality control of raw readings was performed with the FastQC tool (http://www.bioinformatics.babraham.a c.uk/projects/fastqc/). Alignment to the reference genome was performed using TopHat2 software, but since the genome of the Nagasaki strain has not been completely sequenced, the SH0165 strain genome (GenBank accession nr NC_011852.1), also belonging to serovar 5, was used as the reference genome. Transcripts assembly was performed with the Cufflinks tool and transcripts merge with the Cuffmerge tool. Analysis of differences in gene expression was performed with Cuffdiff. Statistical significance was considered for $p<0.05$ (corrected by the multiple testing Benjamini-Hochberg method). Only genes with a $\log _{2}$ (fold change) being $>10$ were considered for further analyses.

\section{Studies of differentially expressed genes}

Differentially expressed genes were subjected to search in the GenBank database to discard pseudogenes and tRNA genes. GenBank [15] and Uniprot [16] annotation was obtained to genes and proteins differentially expressed. The sequences of the proteins encoded by differentially expressed genes were obtained using QuickGo [17]. Prediction of the protein cellular location was carried out using the CELLO v 2.5 web tool (http://cello.life.nctu.e du.tw/) [18]. Proteins predicted to be related to pathogenesis were searched for using the MP3 web tool (http:// metagenomics.iiserb.ac.in/mp3/index.php) [19]. Proteins that were not identified in the GenBank or Uniprot databases but were considered of interest (predicted to be found on the bacterial surface or related to pathogenesis) were subjected to a study using BLASTp in order to find orthologous proteins in related species and using GenBank or InterproScan databases [20] to find domains of a known function. Databases and BLASTp were also used to verify the protein location that CELLO assigned as belonging to the extracellular and Omp fractions.

Genes upregulated under culture mimetic conditions are referred to as "upregulated under mimetic conditions", while those genes upregulated under control conditions are referred to as "downregulated under mimetic conditions". Only genes with $\log _{2}$ (fold change) was $>10$ blank were considered in the analysis of data.

\section{Gene ontology (GO) term enrichment analysis}

Functional enrichment analysis in terms of gene ontology (GO) of differentially expressed genes was conducted using the DAVID v 6.7 web server (https://david.ncifcrf. gov/home.jsp) [21]. Only the GO terms containing a minimum of five differentially expressed genes were considered and the GO terms that showed a $p<0.05$ (corrected by the multiple testing Benjamini-Hochberg method) were considered significantly enriched.

\section{Additional files}

\begin{abstract}
Additional file 1: Summary of genes that were upregulated under mimetic conditions with a $\log _{2}$ (fold change) $>10$. Indicated findings in GenBank and Uniprot databases of genes that were upregulated under mimetic conditions with a $\log _{2}$ (fold change) $>10$. P indicates that the encoded protein is related to pathogenesis, and NP indicates that there is no relationship with pathogenesis. The location of the protein is indicated with EX (extracellular), OM (outer membrane), PP (periplasmic), IM (inner membrane) or CP (cytoplasmic). * indicates that they are the same protein (PDF $117 \mathrm{~kb}$ ).

Additional file 2: Summary of genes that were downregulated under mimetic conditions with a $\log _{2}$ (fold change) $>10$. Indicated findings in GenBank and Uniprot databases of genes that were downregulated under mimetic conditions with a $\log _{2}$ (fold change) $>10$. P indicates that the encoded protein is related to pathogenesis, and NP indicates that there is no relationship with pathogenesis. The location of the protein is indicated with EX (extracellular), OM (outer membrane), PP (periplasmic), IM (inner membrane) or CP (cytoplasmic). * indicates that they are the same protein (PDF $127 \mathrm{~kb}$ ).
\end{abstract}

\section{Abbreviations \\ Cps: Cytoplasmic proteins; Eps: Extracellular proteins; Fur: Ferric uptake regulatory protein; GO: Gene ontology; Hsp: Heat shock proteins; Imps: Inner membrane proteins; Omps: Outer membrane proteins; Pps: Periplasmic proteins; RNAseq: RNA-sequencing}

\section{Funding}

This work was supported by project AGL2011-23195 from the Spanish Ministry of Economy and Competitivity. AAE was a recipient of long-predoctoral fellowships from this Ministry financed by the project AGL2011-23195.

\section{Availability of data and materials}

All data generated or analyzed during the current study are included in this published article and supplementary information files.

The datasets supporting the conclusions of this article are included within the article and additional files.

\section{Authors' contributions}

AAE and SMM performed the bacterial cultures and the RNA sampling; AAE performed the study of the differentially expressed genes; AAE wrote the paper; SMM, CBGM and EFRF contributed to critical review of the manuscript. All authors read and approved the final manuscript. 


\section{Ethics approval and consent to participate}

Not applicable: H. parasuis Nagasaki strain did not require any administrative or ethical permissions to use it.

\section{Consent for publication}

Not applicable.

\section{Competing interests}

The authors declare that they have no competing interests.

\section{Publisher's Note}

Springer Nature remains neutral with regard to jurisdictional claims in published maps and institutional affiliations.

Received: 10 July 2018 Accepted: 12 October 2018 Published online: 06 November 2018

\section{References}

1. Nedbalcova K, Satran P, Jaglic R, Sondirasova R, Kucerova Z. Haemophilus parasuis and Glässer's disease in pigs: a review. Veterinar Med. 2006;51:168-79.

2. Li J, Wang S, Li C, Wang C, Liu Y, Wang G, He X, Hu L, Liu Y, Cui M, Bi C, Shao Z, Wang X, Xiong T, Cai X, Huang L, Weng C. Secondary Haemophilus parasuis infection enhances highly pathogenic porcine reproductive and respiratory syndrome virus (HP-PRRSV) infection-mediated inflammatory responses. Vet Microbiol. 2017;204:35-42. https://doi.org/10.1016/j.vetmic. 2017.03.035.

3. Liu H, Xue Q, Zeng Q, Zhao Z. Haemophilus parasuis vaccines. Vet Immunol Immunopathol. 2016;180:53-8. https://doi.org/10.1016/j.vetimm.2016.09.002.

4. Ruiz A, Oliveira S, Torremorell M, Pijoan C. Outer membrane proteins and DNA profiles in strains of Haemophilus parasuis recovered from systemic and respiratory sites. J Clin Microbiol. 2001;39:1757-62.

5. Sette A, Rappuoli R. Reverse vaccinology: developing vaccines in the era of genomics. Immunity. 2010;33:530-41. https://doi.org/10.1016/j. immuni.2010.09.017.

6. Darwin AJ. Stress relief during host infection: the phage shock protein response supports bacterial virulence in various ways. PLoS Pathog. 2013;9: e1003388. https://doi.org/10.1371/journal.ppat.1003388.

7. González Plaza JJ, Hulak N, Zhumadilov Z, Akilzhanova A. Fever as an important resource for infectious diseases research. Intractable Rare Dis Res. 2016:5:97-102. https://doi.org/10.5582/irdr.2016.01009.

8. del Río ML, Gutiérrez Martín CB, Rodríguez Barbosa Jl, Navas J, Rodríguez Ferri EF. Identification and characterization of the TonB region and its role in transferrin-mediated iron acquisition in Haemophilus parasuis. FEM Immunol Med Immunopathol. 2005;45:75-86.

9. Parrow NL, Fleming RE, Minnick MF. Sequestration and scavenging of iron in infection. Infect Immun. 2013;81:3503-14. https://doi.org/10.1128/IAI. 00602-13.

10. Melnikow E, Dornan S, Sargent C, Duszenko M, Evans G, Gunkel N, Selzer PM, Ullrich HJ. Microarray analysis of Haemophilus parasuis gene expression under in vitro conditinos mimicking the in vivo environment. Vet Microbiol. 2005;110:255-63.

11. Metcalf DS, MacInnes JI. Differential expression of Haemophilus parasuis genes in response to iron restriction and cerebrospinal fluid. Can J Vet Res. 2007;71:181-8.

12. Xie Q, Jin H, Luo R, Wan Y, Chu J, Zhou H, Shi B, Chen H, Zhou R. Transcriptional responses of Haemophilus parasuis to iron-restriction stress in vitro. Biometals. 2009;22:907-16.

13. Oliveira S. Diagnostic notes Haemophilus parasuis. J Swine Health Prod J Swine Health Prod. 2007;15:99-103 http://www.aasv.org/shap.html. Accessed 21 Nov 2017.

14. Trapnell C, Hendrickson DG, Sauvageau M, Goff L, Rinn JL, Pachter L. Differential analysis of gene regulation at transcript resolution with RNA-seq. Nat Biotechnol. 2012;31:46-53. https://doi.org/10.1038/nbt.2450.

15. Benson DA, Karsch-Mizrachi I, Lipman DJ, Ostell J, Wheeler DL. GenBank. Nucleic Acids Res. 2005;33(Database issue):D34-8. https://doi.org/10.1093/ nar/gki063.

16. The UniProt Consortium. UniProt: the universal protein knowledgebase. Nucleic Acids Res. 2017;45:D158-69. https://doi.org/10.1093/nar/gkw1099.
17. Binns D, Dimmer E, Huntley R, Barrell D, O'Donovan C, Apweiler R. QuickGO: a web-based tool for gene ontology searching. Bioinformatics. 2009;25: 3045-6. https://doi.org/10.1093/bioinformatics/btp536.

18. Lee $\mathrm{S}$, Lee $\mathrm{B}, \mathrm{Kim} \mathrm{D}$. Prediction of protein secondary structure content using amino acid composition and evolutionary information. Prot Struct Funct Bioinform. 2005;62:1107-14. https://doi.org/10.1002/prot.20821.

19. Gupta A, Kapil R, Dhakan DB, Sharma VK. MP3: a software tool for the prediction of pathogenic proteins in genomic and metagenomic data. PLoS One. 2014;9:e93907. https://doi.org/10.1371/journal.pone.0093907.

20. Finn RD, Attwood TK, Babbitt PC, Bateman A, Bork P, Bridge AJ, et al. InterPro in 2017-beyond protein family and domain annotations. Nucleic Acids Res. 2017;45:D190-9. https://doi.org/10.1093/nar/gkw1107.

21. Huang DW, Sherman BT, Lempicki RA. Systematic and integrative analysis of large gene lists using DAVID bioinformatics resources. Nat Protoc. 2009;4: 44-57. https://doi.org/10.1038/nprot.2008.211.

22. Song XM, Forsgren $A$, Janson $H$. Fragmentation heterogeneity of $23 \mathrm{~S}$ ribosomal RNA in Haemophilus species. Gene. 1999;230:287-93 http://www. ncbi.nlm.nih.gov/pubmed/ 10216268. Accessed 21 Nov 2017.

23. Hill CE, Metcalf DS, JIMl. A search for virulence genes of Haemophilus parasuis using differential display RT-PCR. Vet Microbiol. 2003;96:189-202 http://www.ncbi.nlm.nih.gov/pubmed/14519336. Accessed 21 Nov 2017.

24. Goethe R, Gonzáles OF, Lindner T, Gerlach GF. A novel strategy for protective Actinobacillus pleuropneumoniae subunit vaccines: detergent extraction of cultures induced by iron restriction. Vaccine. 2000;19:966-75 http://www.ncbi.nlm.nih.gov/pubmed/11115723. Accessed 21 Nov 2017.

25. Bello-Ortí B, Howell KJ, Tucker AW, Maskell DJ, Aragon V. Metatranscriptomics reveals metabolic adaptation and induction of virulence factors by Haemophilus parasuis during lung infection. Vet Res. 2015;46:102.

26. Frandoloso R, Martínez S, Rodríguez-Ferri EF, García-Iglesias MJ, PérezMartínez C, Martínez-Fernández B, Gutiérrez Martín CB. Development and characterization of protective Haemophilus parasuis subunit vaccines based on native proteins with affinity to porcine transferrin and comparison with other subunit and commercial vaccines. Clin Vaccine Immunol. 2011;18:508. https://doi.org/10.1128/CVl.00314-10.

27. Frandoloso R, Martínez-Martínez S, Calmettes C, Fegan J, Costa E, Curran D, Yu RH, Gutiérrez-Martín CB, Rodríguez-Ferri EF, Moraes TF, Schryvers AB. Nonbinding site-directed mutants of transferrin binding protein $B$ exhibit enhanced immunogenicity and protective capabilities. Infect Immun. 2015; 83:1030-8. https://doi.org/10.1128/IAl.02572-14.

28. Morton DJ, Seale TW, Madore LL, VanWagoner TM, Whitby PW, Stull TL. The haem-haemopexin utilization gene cluster (hxuCBA) as a virulence factor of Haemophilus influenzae. Microbiology. 2007;153(Pt 1):215-24. https://doi.org/ 10.1099/mic.0.2006/000190-0.

29. Wen $Y$, Yan X, Wen $Y$, Cao S, He L, Ding L, Zhang L, Zhou P, Huang X, Wu R, Wen $X$. Immunogenicity of the recombinant HxuCBA proteins encoded by hxuCBA gene cluster of Haemophilus parasuis in mice. Gene. 2016;591:47883. https://doi.org/10.1016/j.gene.2016.07.001.

30. Mikael LG, Pawelek PD, Labrie J, Sirois M, Coulton JW, Jacques M. Molecular cloning and characterization of the ferric hydroxamate uptake (fhu) operon in Actinobacillus pleuropneumoniae. Microbiology. 2002;148(Pt 9):2869-82. https://doi.org/10.1099/00221287-148-9-2869.

31. Hasday JD, Singh IS. Fever and the heat shock response: distinct, partially overlapping processes. Cell Stress Chaperones. 2000;5:471-80 http://www. ncbi.nlm.nih.gov/ pubmed/11189454. Accessed 21 Nov 2017.

32. Koronakis V, Sharff A, Koronakis E, Luisi B, Hughes C. Crystal structure of the bacterial membrane protein TolC central to multidrug efflux and protein export. Nature. 2000;405:914-9. https://doi.org/10.1038/35016007.

33. Li M, Cai R-J, Song S, Jiang Z-Y, Li Y, Gou H-C, Chu PP, Li CL, Qiu HJ. Evaluation of immunogenicity and protective efficacy of recombinant outer membrane proteins of Haemophilus parasuis serovar 5 in a murine model. PLoS One. 2017;12:e0176537. https://doi.org/10.1371/journal.pone.0176537.

34. Deslandes V, Nash JHE, Harel J, Coulton JW, Jacques M. Transcriptional profiling of Actinobacillus pleuropneumoniae under iron-restricted conditions. BMC Genomics. 2007;8:72. https://doi.org/10.1186/1471-2164-8-72.

35. Tegetmeyer HE, Fricke K, Baltes N. An isogenic Actinobacillus pleuropneumoniae AasP mutant exhibits altered biofilm formation but retains virulence. Vet Microbiol. 2009;137:392-6. https://doi.org/10.1016/j.vetmic.2009.01.026.

36. Bodelón G, Palomino C, Fernández LÁ. Immunoglobulin domains in Escherichia coli and other enterobacteria: from pathogenesis to applications in antibody technologies. FEMS Microbiol Rev. 2013;37:204-50. https://doi. org/10.1111/j.1574-6976.2012.00347.x. 
37. Starosta AL, Lassak J, Jung K, Wilson DN. The bacterial translation stress response. FEMS Microbiol Rev. 2014;38:1172-201. https://doi.org/10.1111/ 1574-6976.12083.

38. Carpenter BM, Whitmire JM, Merrell DS. This is not your mother's repressor: the complex role of fur in pathogenesis. Infect Immun. 2009;77:2590-601. https://doi.org/10.1128//Al.00116-09.

39. Ghazaei C. Role and mechanism of the Hsp70 molecular chaperone machines in bacterial pathogens. J Med Microbiol. 2017;66:259-65. https:// doi.org/10.1099/jmm.0.000429.

40. Henderson B, Allan E, Coates ARM. Stress wars: the direct role of host and bacterial molecular chaperones in bacterial infection. Infect Immun. 2006;74: 3693-706. https://doi.org/10.1128//Al.01882-05.

Ready to submit your research? Choose BMC and benefit from:

- fast, convenient online submission

- thorough peer review by experienced researchers in your field

- rapid publication on acceptance

- support for research data, including large and complex data types

- gold Open Access which fosters wider collaboration and increased citations

- maximum visibility for your research: over $100 \mathrm{M}$ website views per year

At BMC, research is always in progress.

Learn more biomedcentral.com/submissions 